\section{Early postoperative myocardial morbidity in patients with coronary artery disease undergoing major non-cardiac surgery: correlation with peri- operative ischaemia}

Ronald D. Seegobin MRCP FRCPC, *

Trevor H. Wilmshurst PhD, $†$ James Johnston, $\ddagger$

Frank Clewlow,§ Anthony Murrills,§

Anand H Seegobin MSc, Frank Goodland,

Chris Wainwright FFarCs, ${ }^{*}$ John Norman PhD FFarCs, ${ }^{*}$ Neville Conway FRCP\|
As a part of a study assessing early postoperative myocardial morbidity in 50 patients with active coronary artery disease undergoing major non-cardiac surgery, the ECG was monitored continuously for $24 \mathrm{hr}$ after the onset of anaesthesia, using a frequency modulated (FM) Holter monitor. Concurrent automated blood pressure and pulse were measured non-invasively at three-minute intervals during anaesthesia and subsequently at five-minute intervals. Thirty patients were monitored with two-site ECG recordings, from modified $V_{1}$ and $V_{5}$ (Group $A$ ). Twenty patients had seventeen-site ECG monitoring, multiplexing a four by four array of precordial electrodes onto one channel of the frequency modulated recorder (Group B). Tapes were analyzed for noise, supraventricular and ventricular dysrythmias, runs of tachy-and bradycardia, and ST segment changes. These data were correlated with serial standard 12-lead ECGs and CK-MB assay in the $72 \mathrm{hr}$ after surgery. Seven tapes from Group A could not be analyzed. Change ( $>I$

Key words

COMPLICATIONS: myocardial infarction;

HEART: ischaemia;

MONITORING: electrocardiography.

From the Departments of Anaesthesia, ${ }^{*}$ Electronics, $\uparrow$

Medical Physics and Medical Engineering, $\S$ Cardiology, $\|$

Chemical Pathology, I University of Southampton; Department of Cardiology, University of Oxford. $\ddagger$

Address correspondence to: Dr. R.D. Seegobin, Department of Anaesthesia, Qucen's University, Kingston, Ontario, Canada K7L 3N6

Supported by a grant from the British Heart Foundation. Dr. R. Secgobin was a British Heart Foundation Research Fellow for the duration of this study.

Accepted for publication 2nd June, 1991. $\mathrm{mm})$ on ST monitoring from both Groups $A(14 / 23), B(14 / 20)$, correlated with serial 12-lead ECG andlor $C K-M B$ changes. The majority of first ST change 19/28 (70\%) occurred after anaesthesia. In 14/28 (50\%) ST change occurred during episodes of tachycardia and elevated blood pressure $(>20 \%$ above baseline). Nine patients (9/23) in Group A had no ST change; however, six had serial 12-lead ECG andlor CK-MB changes. Six patients (6/20) in Group $B$ had no ST changes, and none of these patients had any change of serial 12-lead ECGs or $C K-M B$ assay. No patient complained of chest pain during the Holter monitoring period. Continual monitoring of heart rate and blood pressure and accurate $S T$ monitoring are essential to detect and treat perioperative myocardial ischemia. A multiplelead precordial system is substantially more sensitive than traditional two-lead ECG holter monitoring in detecting myocardial ischaemia.

Au cours d' une étude de la morbidité myocardique postopéra. toire chez 50 candidats à une chirurgie non cardiaque atteints de maladie coronarienne, nous avons enregistré l'ECG avec un moniteur Holter à modulation de fréquence ( $F M$ ) de façon continue pendant 24 hà partir de l'induction de l'anesthésie. On mesurait aussi le pouls et la pression artérielle par oscillométrie aux trois minutes pendant l' intervention chirurgicale et aux cing minutes par la suite. Chez 30 patients, on monitoral'équivalent de $V_{1}$ et $V_{5}$ (groupe $A$ ) alors que chez 20 autres on avait 17 électrodes précordiales arrangées en une matrice de $4 \times 4$ que l'on multiplexait sur un canal du Holter FM (groupe B). Nous avons analysé les enregistrements en fonction du niveau d'interférence, des dysrythmies ventriculaires et supraventriculaires, des episodes de tachy ou de bradycardie et des modifications des segments ST. On mis toute cette information en parallèle avec des ECG à 12 dérivations et des analyses des niveaux de $C K-M B$ répétés pendant les 72 suivant l'interven- 
tion. Sept enregistrements du groupe A étaient inutilisables. Les modifications du segment ST de plus de I mm survenues chez 14 patients de chaque groupe étaient en corrélation avec les trouvailles à l'ECG 12 dérivations et les niveaux de CK-MB. Dix-neuf des 28 épisodes d' altération du segment ST survinrent apres l'anesthésie et 14 d'entre-eux accompagnait une poussée de tachycardie et d'hypertension $>120 \%$ de la valeur contrôle). Neuf des vingt-trois patients du groupe $A$ avaient des segments ST normaux pourtant, six d'entre-eux virent changer leur ECG 12 dérivations etiou leur niveau de CK-MB. Des six patients du groupe $B$ dont les segments $S T$ restèrent inchangés, aucun ne démontra de changement électrocardiographique ou enzymatique. Par ailleurs aucun patient ne se plaint d'angine pendant la période de Holter. La mesure fréquente du pouls et de la pression artérielle et un monitorage précis et continu des segments ST est essentiel à la détection (et au traitement) de l'ischémie périopératoire. Un système ECG à multiples dérivations précordiales est à cet égard beaucoup plus sensible que les deux dérivations utilisées traditionnellement dans le monitorage Holter.

Myocardial re-infarction in patients with proven coronary artery disease presenting for major non-cardiac surgery is held to be maximal on the third day after surgery. ${ }^{1}$ The immediate peri-anaesthetic period presents a haemodynamic stress to the cardiovascular system. The induction period of anaesthesia and the intubation sequence, surgical events and extubation at the end of anaesthesia may cause myocardial ischaemia due to an imbalance of myocardial oxygen supply/demand caused by variation in heart rate and blood pressure. Myocardial ischaemia may also be caused by inadequate perfusion, as may occur with dysrhythmias with associated loss of cardiac output. Such events in the perioperative period may contribute to myocardial damage.

Much non-invasive monitoring during anaesthesia and in the immediate postoperative period centres around the ECG. Frequent ventricular beats are used as a major index of active coronary artery disease. ${ }^{2}$ Many ECG monitors may not have an automatic arrhythmia detection and count facility. Myocardial ischaemia can be reflected by changes in the ST segment of the ECG with careful choice of the monitored lead. ${ }^{3,4}$ The use of smoothing filters may make it impossible to diagnose and quantify accurately any change in the ST segment. Many such monitoring systems are incapable of monitoring more than one lead at a time and may miss ischaemic episodes. ${ }^{3}$ The product of heart rate and systolic blood pressure, the rate pressure product (RPP) may, despite limitations, provide an index of the work of the heart and reflect the stresses on the cardiovascular system. ${ }^{5-8}$ Invasive arterial blood pressure monitoring is not universally available. A non- invasive automated blood pressure monitoring device remains an inexpensive alternative to invasive methods of assessing such stress.

Accurate arrhythmnia analysis and ST monitoring ${ }^{9}$ have become available through Holter monitoring, as has reliable non-invasive monitoring of the blood pressure. Frequency modulated (FM) ECG recorders may provide the most accurate signal for ECG ST segment analysis. ${ }^{10}$ The stresses of the perioperative period can be assessed non-invasively using these two techniques. The siting of such a monitoring lead or leads may be critical to the ability to diagnose myocardial ischaemia. One or two leads of an ECG system may not be adequate. " Standard ECG leads may not detect subendocardial ischaemia. ${ }^{3,12}$ A precordial array of electrodes may be superior to the monitoring of standard leads for detecting subendocardial ischaemia. ${ }^{13-16}$

This prospective study was designed to assess early myocardial morbidity in patients with known coronary artery disease undergoing non-cardiac surgery. It aimed to correlate ECG events from either 2-site or 17-site precordial ECG array of electrodes gathered by FM Holter monitoring, and non-invasive blood pressure monitoring, in the first $24 \mathrm{hr}$ after induction of anaesthesia, with early myocardial morbidity as defined by change in serial CK-MB assay and serial 12-lead ECG's over the first three days after anaesthesia/surgery.

\section{Methods}

\section{Patient selection}

The study was approved by the Hospital Ethics Committee and informed written consent was obtained from all patients. Fifty patients of both sexes, ASA physical status II to IV with either a documented history of previous myocardial infarction, with or without residual ECG changes, or angina, with or without ECG changes, or ECG changes alone undergoing non-cardiac surgery were admitted into this prospective study. Patients with bundle branch block, or on medical therapy liable to affect the ST segment, were excluded. The types of operations have been described. ${ }^{17}$

\section{Study design}

In the hour before anaesthesia, patients had their Holter monitoring electrodes applied. The first 30 patients had two-channel ECG Holter monitoring, using an Oxford Medilog 2 FM tape recorder (Oxford Medical Systems, Abingdon, Oxford, England). The five electrodes were placed as recommended by the manufacturers. This allowed a modified precordial lead $V_{5}$ to be recorded on channel 1 and a modified precordial lead $V_{1}$ on channel 2 (Figure 1). This tape system provided $24 \mathrm{hr}$ of recording 


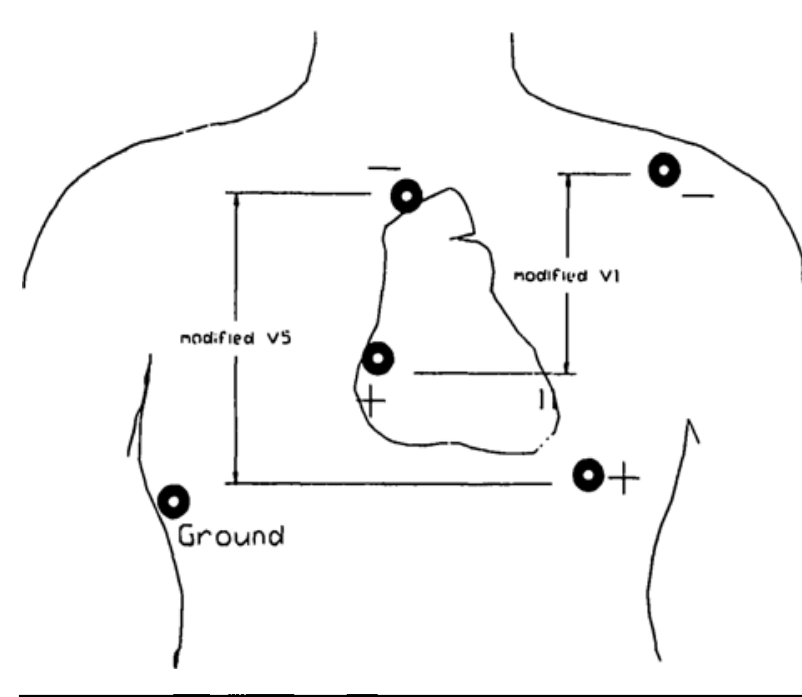

FIGURE 1 Placement of ECG leads for 2-site ECG holter monitoring.

time. During this study period a 16-channel multiplexing unit was designed and tested by the Department of Medical Physics and Medical Engineering at the University of Southampton.

The next 20 patients in the study were monitored from 17 precordial sites. Channel 1 gave a modified lead I, recorded continuously, and channel 2 stored the signals from a 16-site precordial map ${ }^{15}$ with electrode placement, as a four by four equidistant array from the right parasternal border at the angle of Louis to the mid-axillary line (Figure 2). The signals were pre-processed with the 16-site multiplexing unit, and stored on one channel of the FM recorder. The dwell time was six seconds per channel allowing a serial sweep across the chest leads every 96 sec.

Patients continued their current medical therapy. The peri-anaesthetic management has been described in an accompanying paper. ${ }^{17}$ Blood pressure was measured non-invasively using a Bard Sentry automatic blood pressure monitor (Bard Medical, New Jersey USA) every three minutes during anaesthesia and at five-minute intervals thereafter for $24 \mathrm{hr}$, with the data recorded by a thermal printer. After anaesthesia patients were managed in an ICU environment for at least $24 \mathrm{hr}$ or longer as clinically indicated. Blood loss was replaced as necessary to maintain normal haemoglobin levels, and daily haemoglobin and serum electrolytes were measured at the time of each enzyme assay, for three days. In the $24 \mathrm{hr}$ after anaesthesia patients received a titrated iv morphine infusion for pain control. This was continued into the second day if clinically indicated.

\section{Laboratory tests}

The $24 \mathrm{hr}$ ECG tapes were analyzed in the Department of

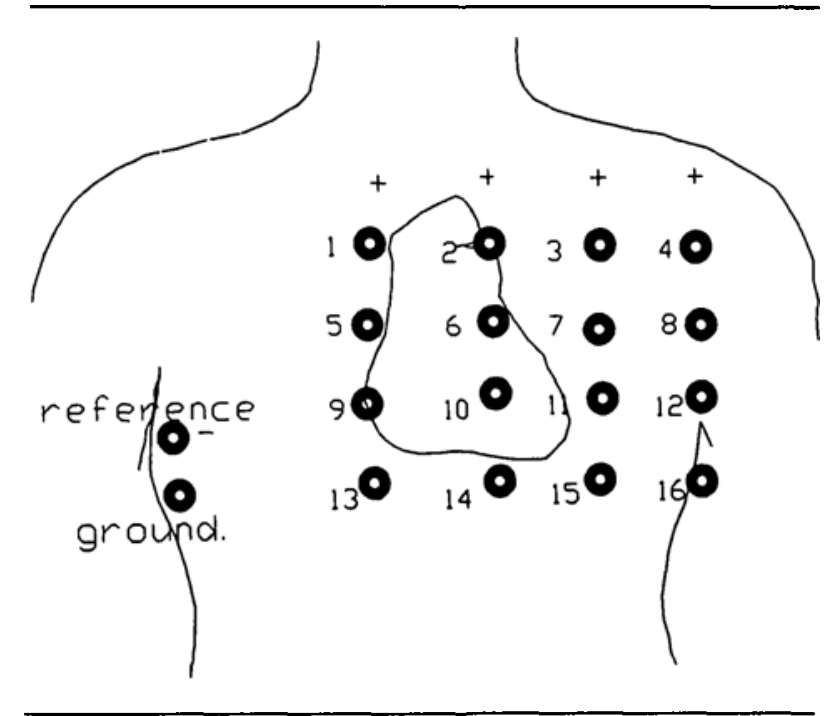

FIGURE 2 Placement of leads for 16-site multiplexed ECG Holter monitoring.

Cardiology at the University of Oxford. The tapes were replayed through an Oxford Medilog PB4 replay unit (Oxford Medical Sytems, Abingdon, Oxford, England) and the extracted signals analyzed through a computerbased system consisting of eight Z80 microprocessor boards in parallel. Each processor could analyze two separate ECG waveform shapes. Arrhythmias were related to the typical ECG waveform in terms of shape of atypical beat, and its timing. An arrhythmia was confirmed by simultaneous presence on both channels. For ST calculations, a 32-point template defined the ECG complex, the T-P segment was used as the base line and the ST segment was sampled beyond the $\mathrm{J}$ point. To compensate for changes in heart rate the initial sampling point used was $1 / 8$ the RR interval, and subject to visual operator control. The ECG was printed during each ischaemic episode for visual manual analysis and crossreference with the automated analysis. The tapes were also analyzed for periods of excessive noise with loss of signal, the presence of premature beats and the presence of ectopic ventricular beats, as well as runs of brady- and tachyarrhythmia. Each event of dysthythmia was recorded for visual confirmation. The tapes were analyzed without knowledge of the patients' clinical course and the results of CK-MB analysis and serial standard 12-lead ECGs.

The results of ST analysis were presented in graphical form against a $24 \mathrm{hr}$ time base with periods of noise, dysrhythmia and tachy and brady episodes displayed for cross-correlation with ischaemic episodes. Arrhythmia count per hour in terms of ectopic beats per hour was also recorded. The ST segement change was considered to be significant if ST change greater than $1 \mathrm{~mm}$ occurred lasting for at least three minutes. This latter time scale was 
chosen arbitrarily due to the $96 \mathrm{sec}$ sweep time across the chest leads and the need for validation of ischaemia over two sampling intervals per precordial site. From the automated blood pressure and pulse recordings, data for systolic, diastolic, mean arterial pressure and pulse rate were plotted on the same time base as the ST analysis, as well as percentage variation of each variable against baseline values. Change was considered to be important if baseline recordings changed by more than $20 \%$. The intermittent nature of the blood pressure monitoring limited the cross-correlation with ST change; however, the duration of ST change episodes allowed an assessment of myocardial work during such episodes.

Using a computer-aided design program (Autocad 10) capable of three-dimension plotting (3D), the events of ST change during 16-channel precordial ECG monitoring were reconstructed by plotting the recordings from each site on the $X Y$ axis, and time on the $Z$ axis. The ST segment change was plotted in a 3D array of four by four to represent the lead configurations of the chest. Four horizontal planes were formed to recreate the events on leads $1-4,5-8,9-12,13-16$, with a fifth plane below to show the changes in heart rate over $24 \mathrm{hr}$ on the same time axis. From the polylines of ST change, using the mesh facility of Autocad, a surface mesh was plotted for each plane of lead placement. Once created this mesh can be treated as a solid object and explored from infinite perspectives.

Blood taken for CK and CK-MB assay at $0,4,24,48$, and $72 \mathrm{hr}$ after anaesthesia was stored and analyzed in batch assay. Serial standard 12-lead ECGs were recorded preoperatively and for the three consecutive days after anaesthesia and were reported without knowledge of the results of other observations. The criteria for enzymatic and ECG ( $Q$ and non $Q$ ) diagnosis of infarction have been previously described. ${ }^{17}$

\section{Results}

\section{2 site ECG group (30 patients)}

In the 2 ECG lead group, seven patient tapes could not be analyzed due to tape recorder and/or power supply malfunction. Of this group of seven patients, six showed serial CK-MB change, four showed serial ECG change (3 non $Q$, and $1 Q$ change) with three patients having concurrent ECG ( 2 non $Q$ and $1 Q$ change) and cardiospecific enzyme change.

Of the 23 tapes that were analyzed, nine patients showed no ST change on either ECG lead. In this group three patients showed serial ECG change ( 2 non $Q$ and 1 Q); four showed serial enzyme change, with one showing concurrent ECG and enzyme change (Q). The remaining 14 patients in this group showed ST change. In this group 12 patients showed serial ECG change (4 non Q, 8 Q); 12

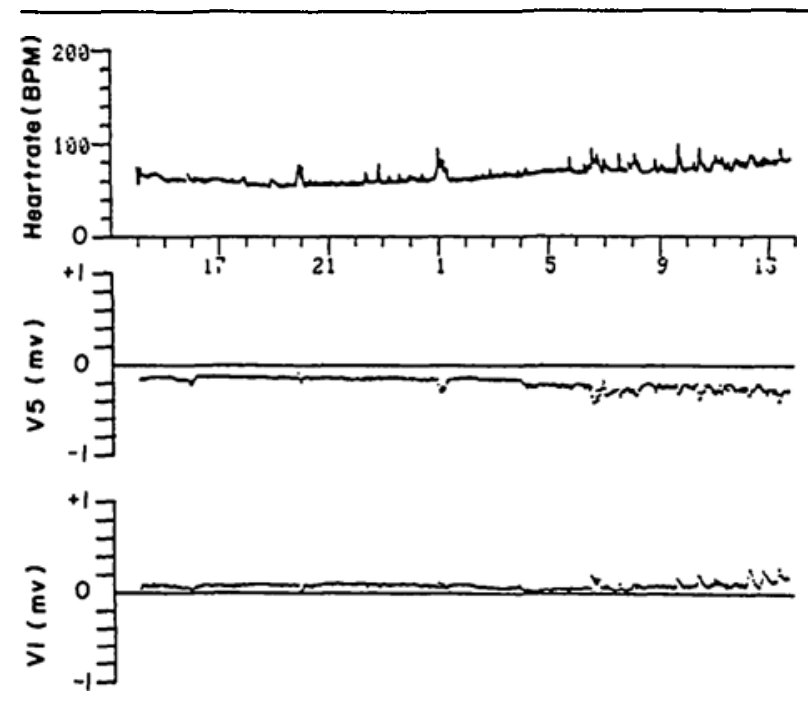

FIGURE 3 Example of heart rate related ST changes from 2-site ECG monitoring in the $\mathbf{2 4} \mathrm{hr}$ after start of anaesthesia. The upper graph has heart rate as derived from the ECG on the $Y$ axis, scaled in 20-beat increments, with time on the $X$ axis, scaled at 1-hr increments. The $X$ axis is common for all three graphs. The lower two graphs plot $S T$ change per channel. The $Y$ axis scale in the lower two graphs is $\pm 1 \mathrm{mV}$ in $0.2 \mathrm{mV}$ increments. Compare with Figure 6 .

patients showed serial cardiospecific enzyme change with 11 patients showing concurrent ECG and enzyme changes (4/4 non $Q$ and 7/8 Q). In seven of the patients ST change was related to changes in the heart rate and blood pressure and in the others ST change occurred in the absence of a change in heart rate, mean arterial pressure, systolic or diastolic blood pressure. The rate pressure product was inappropriate as an indicator of increased risk of ischaemia in half of our patients.

Figures 3 and 4 demonstrate the two types of ST change seen. Figure 3 shows an example of heart rate related ST segment changes. Anaesthesia occurred during the first two hours. At the end of anaesthesia at $1600 \mathrm{hr}$ an ischaemic episode is seen in $V_{5}$. This resolves. Episodes of tachycardia at $2000 \mathrm{hr}$ and $0100 \mathrm{hr}$ precipitate ST change in $V_{5}$. There is further ST segment depression with each subsequent event of increase in heart rate. Increases in heart rate were often associated with a rise in blood pressure. Figure 4 shows an example of ST segment change in the absence of change in heart rate. Anaesthesia occurred in the first $90 \mathrm{~min}$. Episodes of ST change in $\mathrm{V}_{5}$ occurred in the absence of significant change in heart rate, systolic, diastolic or mean blood pressure over the next $24 \mathrm{hr}$. Two patients died in the acute perioperative period. Figure 5 shows the progression of ischaemia, in one patient up to the point of death, in both ECG leads in the absence of tachycardia. This patient showed a marked absence of dysrhythmias on ECG analysis. Systolic blood pressure remained unchanged during progressive ischaemia. 


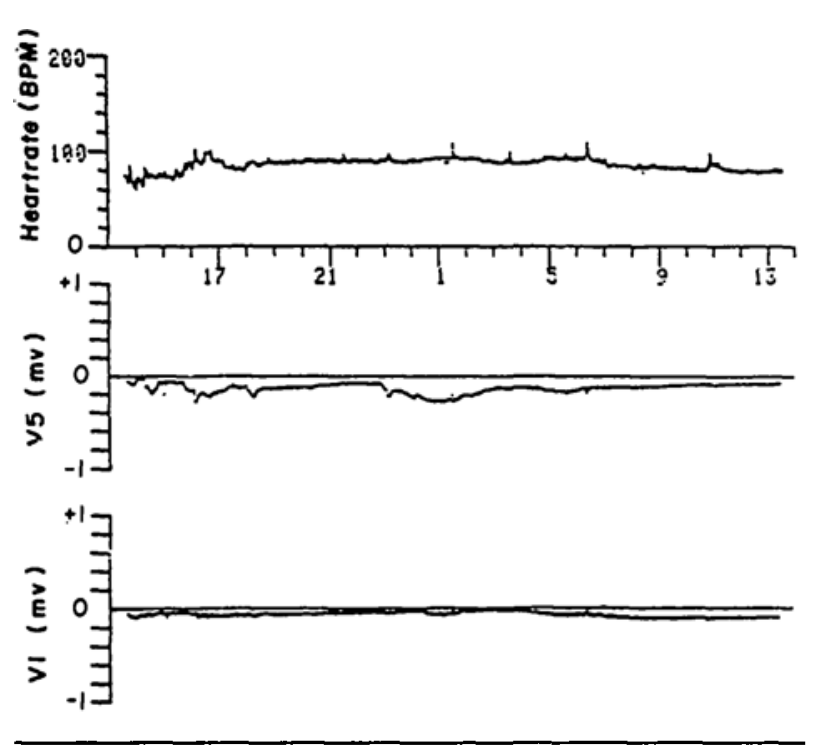

FIGURE 4 Example of 2-site ST segment change in the $24 \mathrm{hr}$ after start of anaesthesia. The axes of the graphs are identical to Figure 3. Ischaemic episodes are independent of heart rate.

\section{7 precordial site ECG group (20 patients)}

Six patients with 17-lead ECG analysis showed no changes in ST segment and there were no serial 12-lead ECG or cardiospecific enzyme changes in these six patients over $72 \mathrm{hr}$. Of the remaining 14 patients, seven showed heart rate and blood pressure related ischaemia and in the remaining seven ischaemia seemed to be independent of change in heart rate, systolic, diastolic or mean blood pressure. All 14 patients, who showed ST change on their 16-site precordial map, had serial standard 12-lead ECG change (10 non Q, 4 Q). Seven of 14 patients showed serial concurrent cardiospecific enzyme change ( 5 non $\mathrm{Q}, 2 \mathrm{Q}$ ). The findings of heart rate related and heart rate independent ST change were similar to those in the two-site monitored group. Examples of such ischaemia are shown in Figures 6 and 7 respectively.

Figure 6 shows an example of the XY plots of ST change in the 16 leads over $24 \mathrm{hr}$ in a patient showing heart-rate related ischaemia. Anaesthesia lasted for $3 \mathrm{hr}$ at the start of this recording. Ischaemic episodes were noted in leads 12 and 16 in the absence of an increase in heart rate. The interpretation of the changes seen on these 16 $X Y$ plots is not intuitive. Using the 3D method of construction and display of the 16-lead ECG ST segment with the meshing technique (Figures 7 and 8), it becomes much clearer that ischaemia occurs with tachycardia, with recruitment of ischaemic area occurring with each subsequent epidsode of tachycardia. Figure 7 shows such a mesh in plan view. This shows the extent of the recruitment of, and extent of, ischaemia with each increase in heart rate.

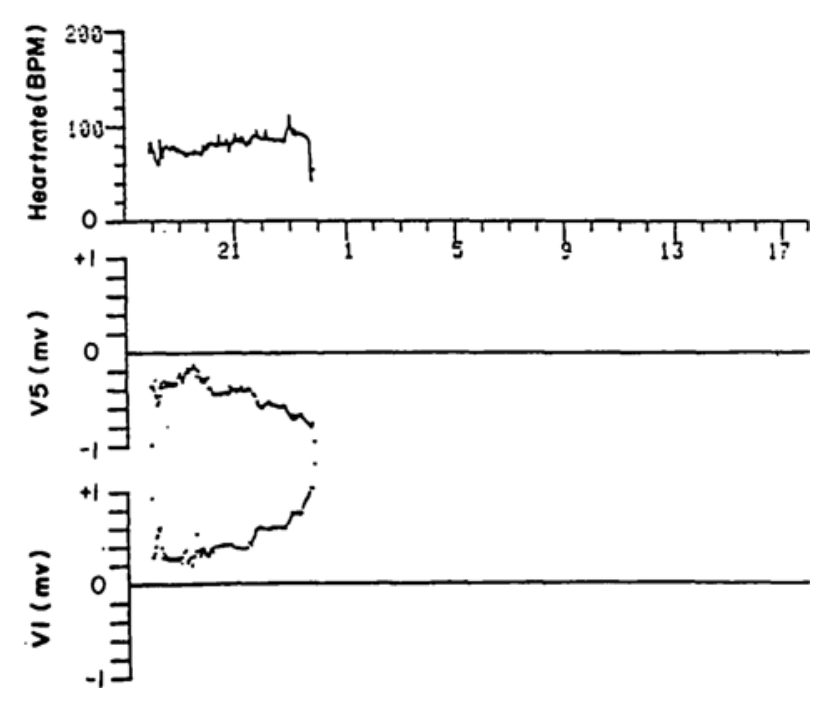

FIGURE 5 Two-site ST change of a perioperative death with progressive ischaemia in the absence of tachycardia. The axes of this graph are identical to Figure 3.

Using the ability of Autocad 10 to give varying perspectives of a 3D structure, Figure 8 gives a bird's eye view of all five meshes from a perspective lateral to the lateral leads. This allows the depth of ST change and the recruitment of ischaemic area to be visualised in relation to changes in heart rate, also plotted as a mesh. At points $a, b, c, d, e$, and $f$, in Figures 6 and 8, maximum heart rate, systolic blood pressure and RPP as recorded noninvasively at five-minute intervals were $(>20 \%)$ elevated above baseline values.

Figure 9 shows an example of a patient who showed ST change in the absence of change in heart rate or systolic pressure of RPP. Anaesthesia lasted the first $2 \mathrm{hr}$ of this recording. In Figure 9 leads 4, 8, 11, 12, 15, and 16 show progressive ST change as time progresses in the absence of any change in heart rate. At 2300 hours an event occurred which recruits a larger area of ischaemia. The compromised myocardium then seemed incapable of accommodating the slightest increase in heart rate. Figures 10 and 11 show the data from Figure 9 presented in $3 \mathrm{D}$ format. Figure 10 give a plan view at right angles to the generated 3D mesh and Figure 11 gives a bird's eye view from a viewpoint identical to that of Figure 8. At points a, b, c, d, e, on Figures 9 and 10, maximum values of heart rate, systolic blood pressure and RPP were not $(<>20 \%)$ changed.

In none of the 43 tapes analyzed were ischaemic episodes related to or precipitated by concurrent dysrhythmias, either brady, tachy, supraventricular or ventricular arrhythmias. Hourly ventricular arrhythmia count showed that no patient had more than 240 ventricular premature 


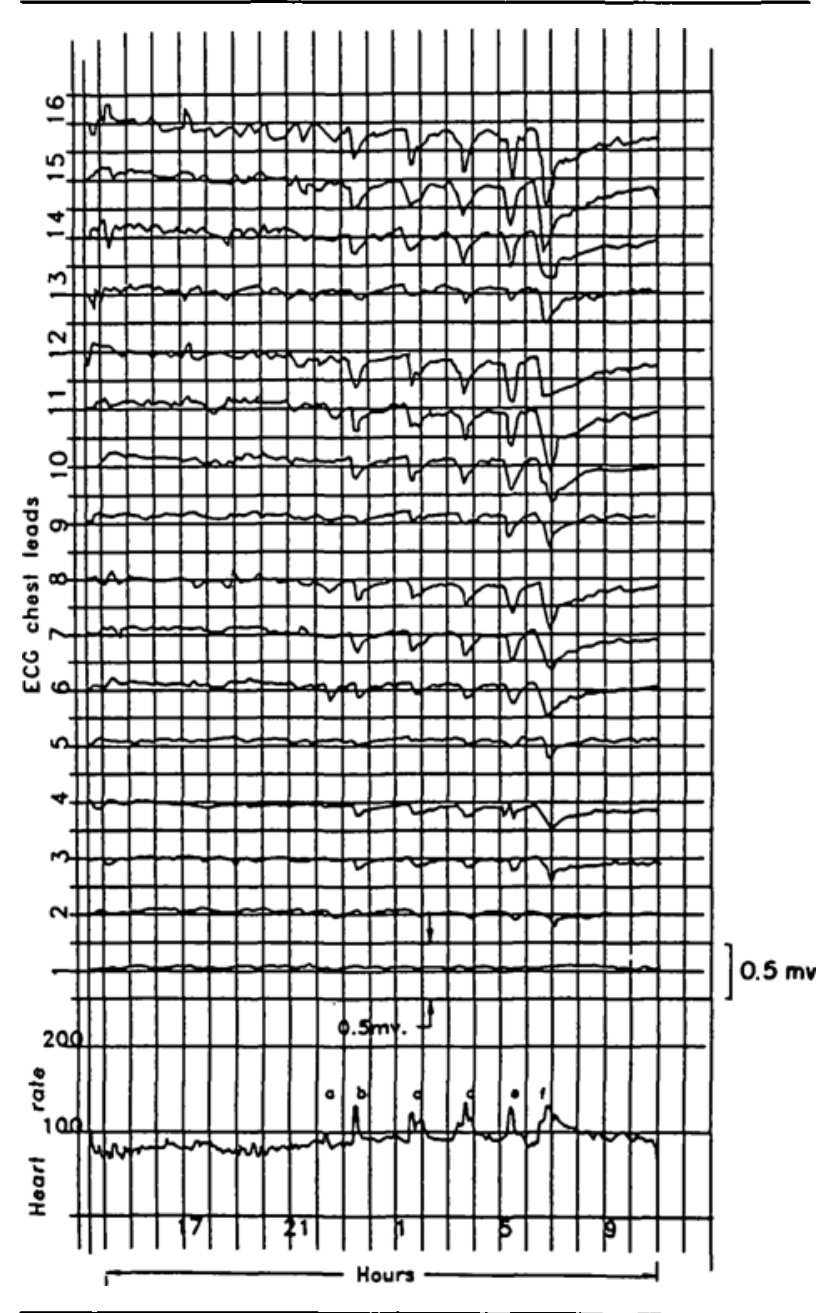

FIGURE 6 ST segment change in the $24 \mathrm{hr}$ after start of anaesthesia, from 16 precordial sites. The two sets of data share the same $X$ axis of time at hourly intervals. The upper graph plots ST data from each of the 16 precordial sites with a range on the $Y$ axis $\pm 0.25 \mathrm{mv}$ per site. The lower graph plots heart rate with a scale of 0 to 200 on the $\mathrm{Y}$ axis. Progressive ST segment correlates with recurrent tachycardia at points a-f.

beats per hour. Ischaemic episodes did not precipitate arthythmias. Ischaemic episodes, if reversible, lasted on average $10-15 \mathrm{~min}$. In 10/28 (30\%) patients who showed ST change on Holter monitoring, including the two deaths, ischaemia first occurred during anaesthesia. The induction/intubation period as well as the extubation sequence at the end of anaesthesia, with the associated changes in heart rate and blood pressure, precipitated ischaemic episodes. In the remainder, $18 / 28(70 \%)$, ischaemia occurred at a varying interval after anaesthesia.

\section{Discussion}

In our group of patients, with a history of coronary artery disease, morbidity in terms of ECG and or enzyme

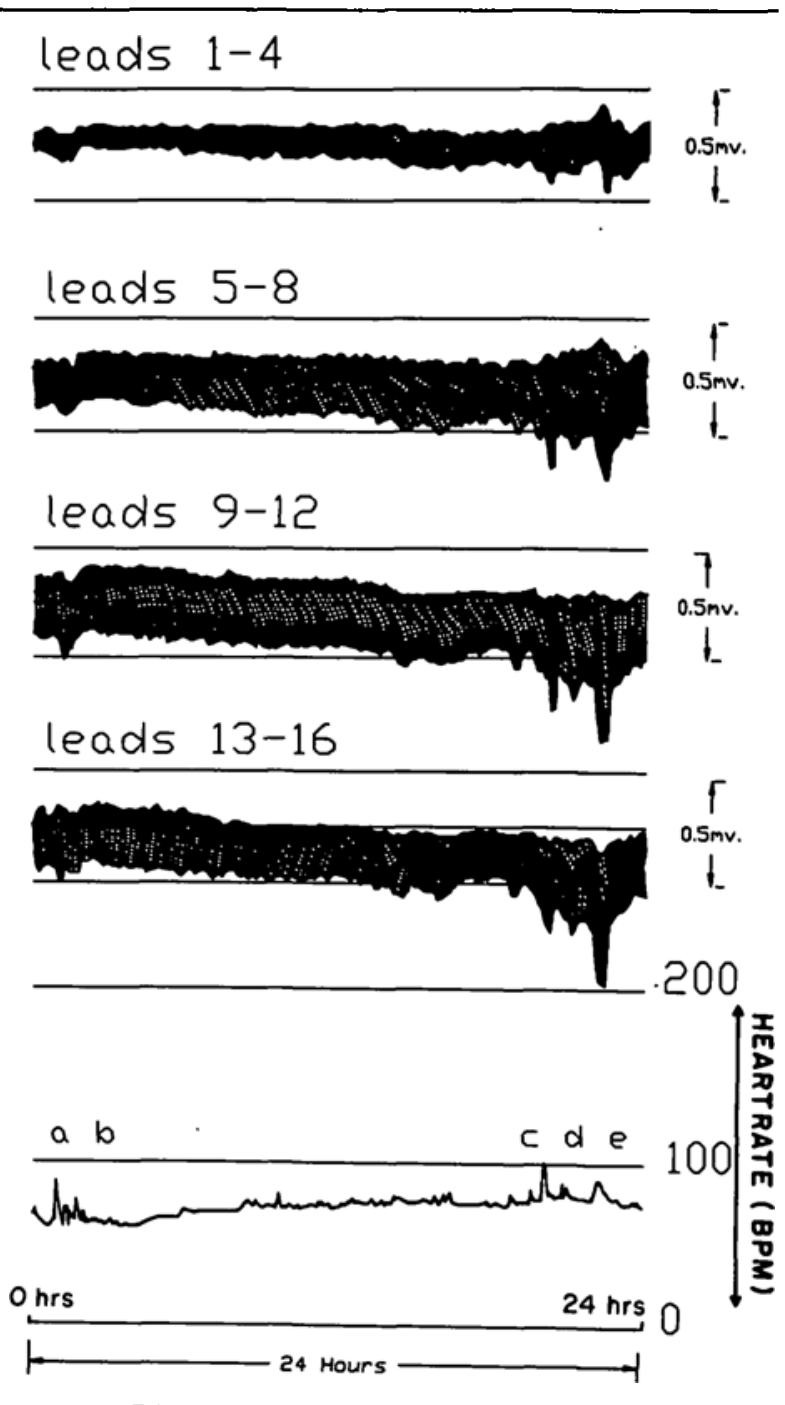

FIGURE 7 ST data from Figure 6 presented as a plan view with a wire frame mesh laycred over a spatial plot of the ST data.

This clearly shows the recruitment of an ischaemic area that occurs with each episode of tachycardia.

change $^{17}$ seemed to follow myocardial ischaemia as evidenced by ST segment change in the 24 hours after anaesthesia. We also found that patients suffered myocardial ischaemia and damage in the absence of a substantial frequency of ventricular beats $\left(>240 \cdot \mathrm{hr}^{-1}\right)$ and of ventricular dysrhythmia, either as cause or effect. In half of the patients ST change was related to changes in heart rate and increase in blood pressure and in the other half ST change occurred in the absence of change in heart rate, systolic, diastolic and mean blood pressure. In either event once ischaemia had occurred, in both groups of patients, tachycardia was tolerated poorly resulting in further recruitment of ischaemic area. Only $30 \%$ of our patients showed ischaemia during anaesthesia. 


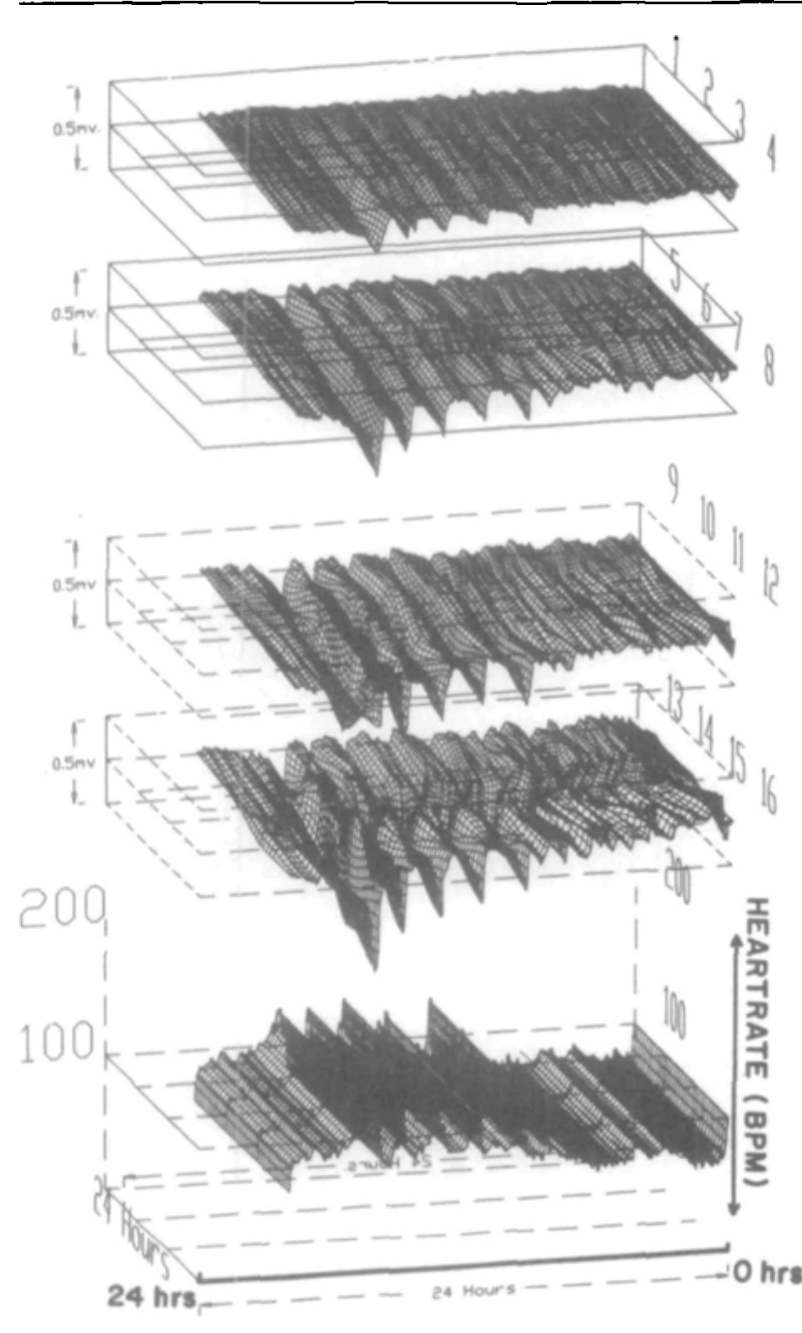

FIGURE 8 View of the ST segment depression from Figure 6, presented as a wire frame mesh overlaying each group of four electrodes. The perspective is lateral to leads $4,8,12$, and 16 . Note that time begins at the right and moves to the left.

Most ECG and/or CK-MB change (85\%) occurred in the first $24 \mathrm{hr}$. These findings are similar to those reported by Raby et al. ${ }^{18}$ and at variance with other studies. ${ }^{1,19}$ Only one patient showed the first signs of damage on the third day. In our two patients who died ischaemia was progressive and irreversible. Savage et al. ${ }^{20}$ reported ischaemia in $66 \%$ of patients who died of sudden death during ambulatory monitoring. Though myocardial morbidity ( $44 \%$ correlative ECG/CK-MB change) was high in this study, mortality was low compared with other series. Similar findings of high morbidity have been reported by Fleisher et al. ${ }^{21}$ and are higher than those reported by Raby et al. ${ }^{18}$ This variation may be due to different populations being studied. The majority of patients in this study $(84 \%)$ of the patients in this series were having non-cardiac vascular surgery. These patients may have

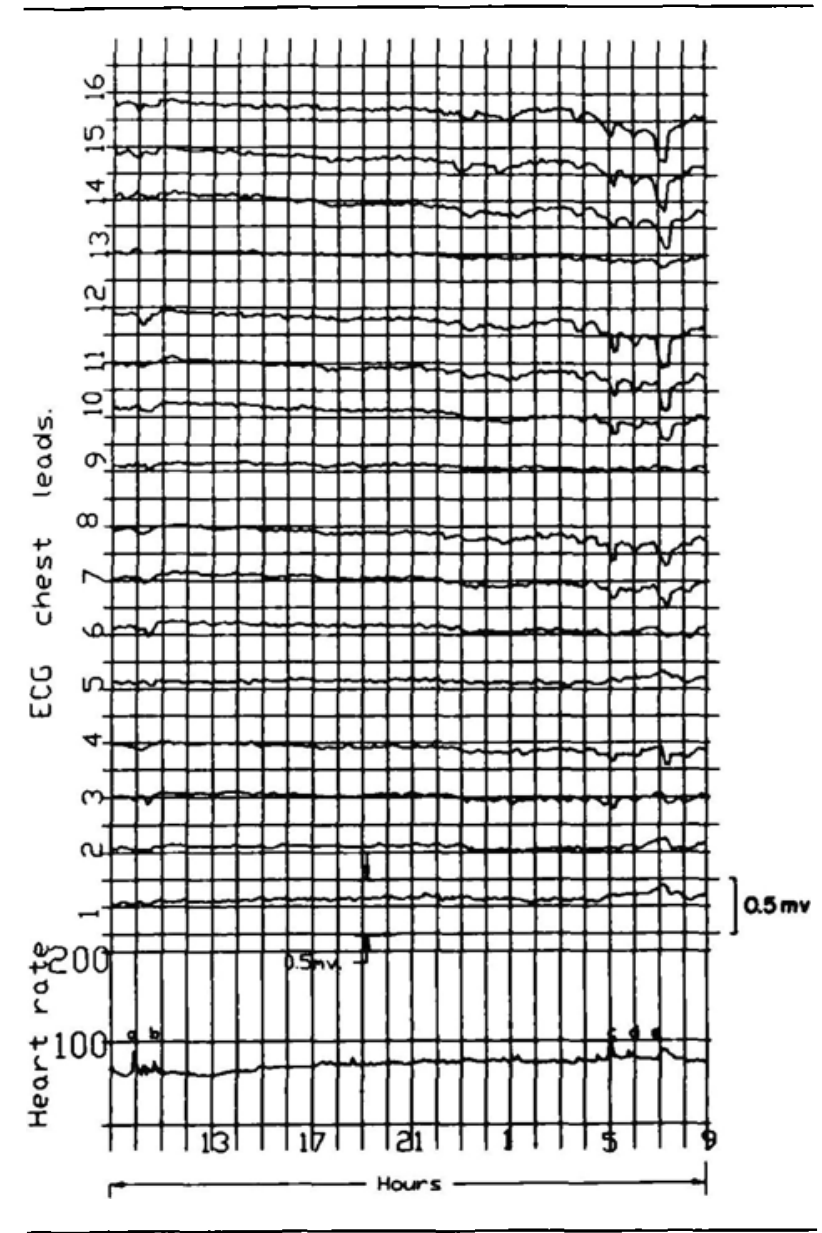

FIGURE 9 ST segment change from 16 precordial sites in the 24 hours after anaesthesia. The axes of this graph are identical to Figure 6. Precordial ST change is independent of heart rate until points $c, d, e$.

severe coronary artery disease masked by their surgical pathology. This may be reflected in the high morbidity in these patients. These patients may represent one end of a widely varying spectrum of patients with coronary artery disease. The lower morbidity in other studies may reflect a wider range of patients with a broader spectrum of coronary artery disease.

Two-site monitoring, using modified $\mathrm{V}_{1}, \mathrm{~V}_{5}$, did not elicit ischaemic episodes in $25 \%$ of patients with serial ECG and/or CK-MB changes. These results are comparable with the findings of Krucoff ${ }^{11}$ in his studies of temporary coronary occlusion during balloon angioplasty, when $V_{5}$ monitoring failed to show ischaemia during balloon occlusion in $33 \%$ of patients. Precordial monitoring from sixteen sites demonstrated all episodes of ischaemia. No patients with a normal ST profile from the 16 channels showed serial ECG or CK-MB changes over the next 72 hours. Body surface mapping has been extensively reviewed. ${ }^{22-24}$ The 16 -site precordial system 


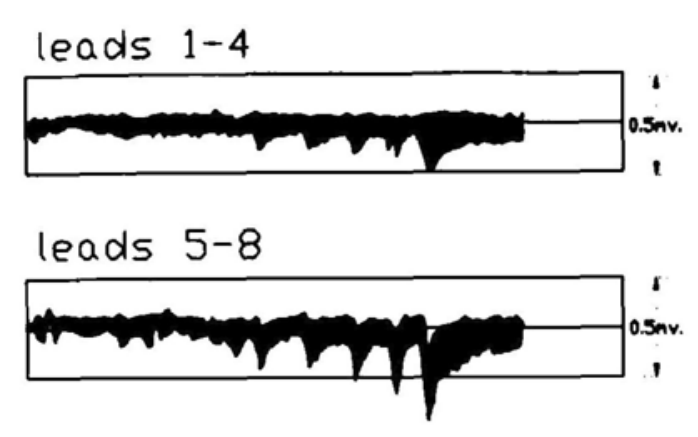

leads $9-12$
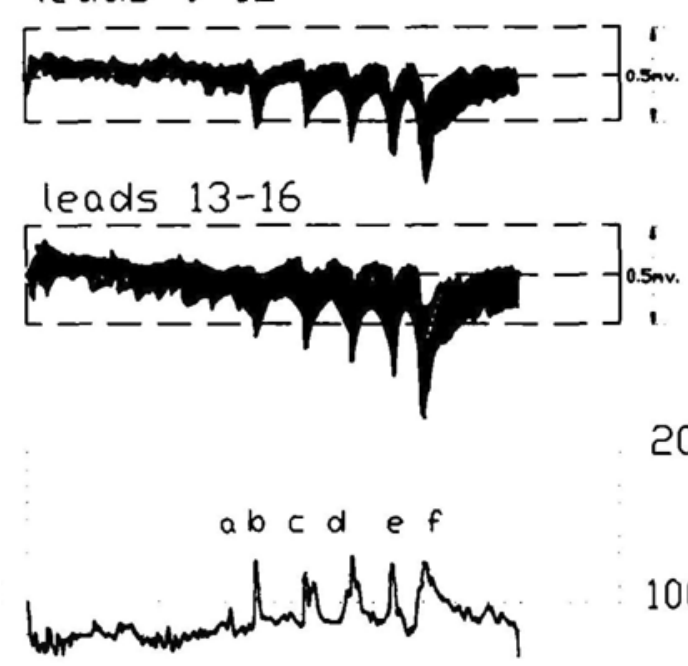

100

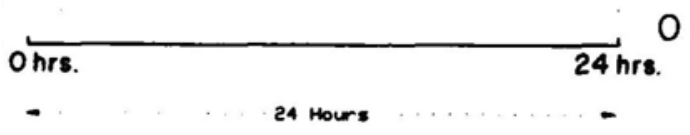

FIGURE 10 ST data from Figure 9 presented as a plan view Progressive ischaemia occurs during the $24 \mathrm{hr}$ of monitoring, with ratedependent ischaemia occuring at points $c, d, e$.

of Fox et al. ${ }^{15.16}$ was chosen to reflect changes in the ST segment in the distribution of each of the major coronary arteries. Though no direct comparison is possible between the 2-site and 17-site groups, the inability of the $V_{5}$ lead to detect ischaemia may be explained in part by the precordial projection of the left circumflex artery. ${ }^{16}$ Ischaemia in the distribution of this artery may be missed by $V_{1}$ and $V_{5}$ monitoring.

In contrast to two-channel recordings, precordial mapping also provides further understanding of the process of ischaemia, by showing in 3D meshes the recruitment of myocardial ischaemic area that occurs with each cardiovascular stress. The presentation of time-based data in a 3D mesh format provides a more intuitive understanding

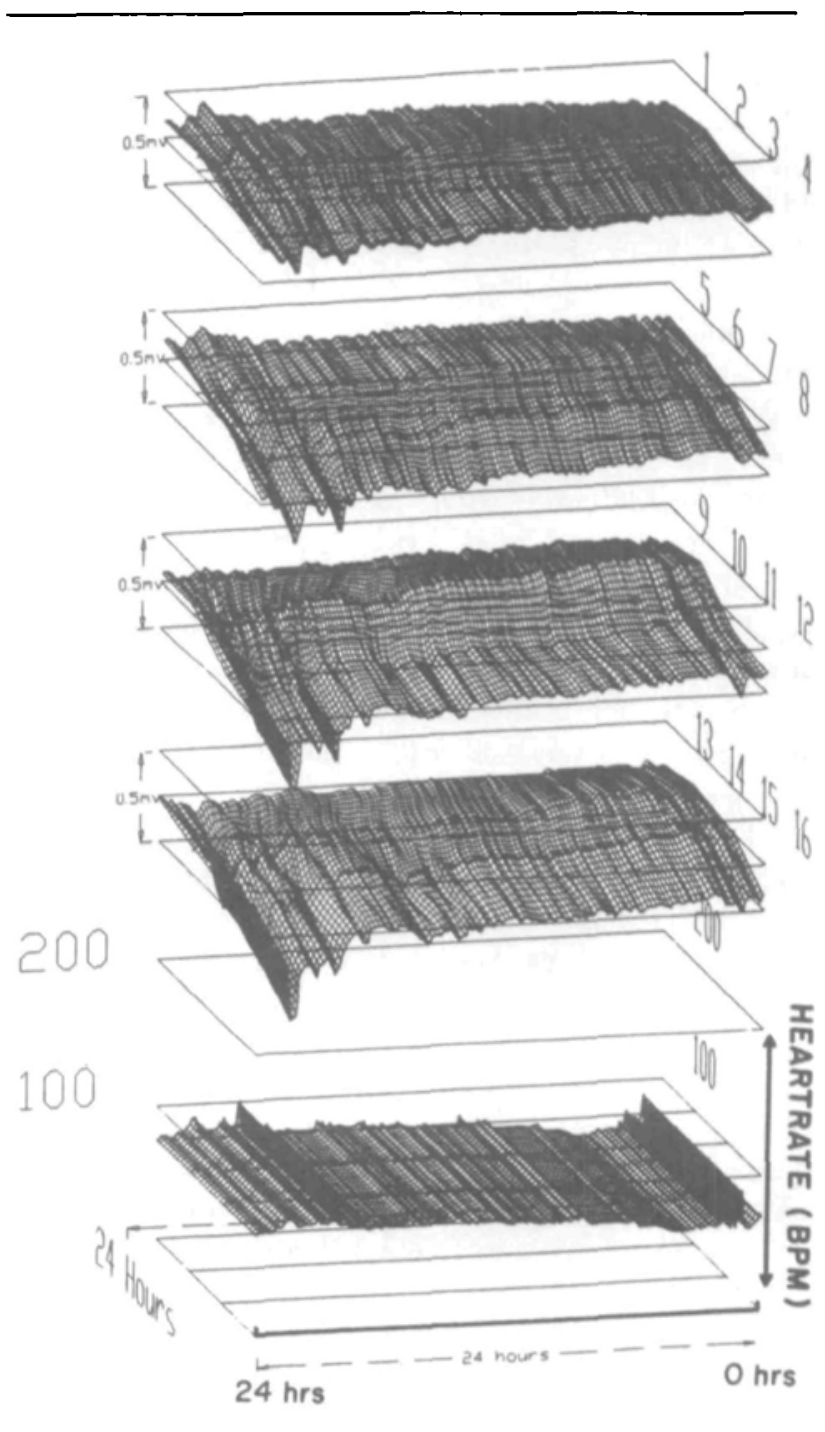

FIGURE 11 View of ST segment change from Figure 9 presented as a wire framed mesh overlaying each group of four electrodes. The perspective and time axis is identical to Figure 9.

of ischaemic episodes than contour maps. ${ }^{25,26}$ Our results suggest that critical damage may occur when the slope of recovery from each ischaemic episode reaches a critical value. This may lead to the development of an index of a critical area of ischaemia and/or index of recruitment, beyond which infarction occurs. The recovery slopes can be inferred from Figures 8 and 10. Data on ST change have been presented in a planar fashion, reflecting the four by four grid array; however, the data set can also be presented in terms of ST change in the distribution of the right coronary, left circumflex, and left anterior descending coronary arteries.

Our ischaemic episodes were either progressive or lasted a minimum of ten minutes. This onset and duration 
may be a reflection of the basic pathology, ${ }^{27}$ the duration of increased work of the heart, ${ }^{28}$ or the atypical response of atheromatous coronary arteries to stress. ${ }^{29-31}$ Some of the observed ischaemic changes occurred during episodes of tachycardia. Most coronary perfusion occurs in diastole. Boudoulas et al. ${ }^{32}$ have shown that there is a non-linear relationship between heart rate and total diastolic period, and that small increases in heart rate can produce significant reduction in the diastolic period. This may explain the extreme intolerance of tachycardia that we have shown in our study, as in these patients shortening of diastole would precipitate a supply/demand imbalance. It has been shown in the healthy animal model, that precipitating repeated myocardial ischaemia by restricting circulation temporarily to areas of the myocardium, followed by re-perfusion, after a varying number of such insults, eventually leads to myocardial damage..$^{33}$ This may well be the sequence of events shown in Figures 3, 4, 6, 7, when demand outstrips supply.

The patients who showed progressive myocardial ischaemia without a change in rate pressure product may have had stunned myocardium. ${ }^{34,35}$ We did not have preoperative echocardiograms of these patients. Deanfield et al $^{36}$ have shown in patients with active coronary artery disease with and without symptoms of chest pain, that ST ischaemia relates to compromised myocardium as defined by stress thallium and echocardiographic evidence of myocardial dysfunction as evidenced by abnormal wall motion. In our study there was a marked absence of chest pain to accompany myocardial morbidity. This in part may be due to the use of a continuous iv infusion of morphine to control the pain of surgery, and silent ischaemic episodes in a surgical population base with active coronary artery disease. Up to $75 \%$ of myocardial ischaemic episodes with ambulant Holter monitoring of the general medical population with coronary artery disease may be silent. ${ }^{37,38}$ In the Holter study of surgical patients reported by Raby ${ }^{18}$ myocardial ischaemia was silent in $97 \%$ of patients.

The natural history and progression of coronary artery disease after a myocardial infarction remains unquantified. ${ }^{39}$ Patients presenting for surgery are subject to stress to the cardiovascular system. In patients with active coronary artery disease this stress may precipitate a further infarct. Can such patients' risk of further damage be predicted? Active coronary artery disease can be elicited by exercise testing, and as an alternative,${ }^{40}$ stress thallium scans, atrial pacing, beta-adrenergic agonist stimulation, echocardiography, cold pressor testing, isometric exercise, and also by ambulant ST segement monitoring. ${ }^{18}$ It has been suggested that this last technique is as sensitive as any other. ${ }^{41-43}$ Preoperative assessment may be helped by ambulant Holter ST monitoring ${ }^{18,21}$ or preoperative stress-testing with either a cold stimulus, which triggers increases in blood pressure and pulse, ${ }^{44}$ or stimulation of heart rate by atrial pacing or iv chroniotropic agents. ${ }^{45}$ For patients with coronary artery spasm, this may be elicited by stressing with intravenous ergonovine maleate. ${ }^{44}$ The design of this study did not include preoperative Holter monitoring. We cannot say whether these ST changes were totally new in relation to the preoperative stress, or whether they were a progression of preoperative events. If these patients had active coronary artery disease then they would have most likely had preoperative ST changes if monitored by Holter techniques. Support for this supposition has come from studies which have shown that preoperative ST changes with Holter monitoring correlated with further postoperative myocardial damage in patients with a positive cardiac history presenting for non-coronary arterial surgery.

With the high incidence of silent myocardial morbidity and the timing of silent ischaemia (70\% episodes first occurred after anaesthesia) that we have shown, this study suggests that, in the perioperative period, ST segment monitoring is essential as an indicator of patients' risk of further myocardial damage. Many monitors presently used in the operating room and in the recovery room and intensive care units do not have this capability. Single or double lead placement may not identify all episodes of myocardial ischaemia, ${ }^{11}$ nor can they begin to quantify the area of myocardium becoming ischaemic. Precordial mapping using a 16-lead system in this study identified all important ischaemic episodes, as wcll as demonstrating the recruitment of ischaemic area that occurs when jeopardised myocardium is stressed. Such a lead system may improve the sensitivity and specificity of any ECG monitoring system for perioperative monitoring.

\section{References}

1 Tarhan S, Moffitt EA, Taylor WF, Guiliani ER. Myocardial infarction after gencral anaesthesia. JAMA 1972; 220: $1451-4$.

2 Goldman L, Caldera DL, Nussbaum SR et al. Multifactorial index of cardiac risk in non cardiac surgical procedures. N Engl J Med 1977; 297: 845-50.

3 Kaplan JA, King SB. The precordial electrocardiographic lead (V5) in patients who have coronary artery disease. Anesthesiology 1976; 54: 570-4.

4 Roy WL, Edelist G, Gilbert B. Myocardial ischacmia during non-cardiac surgical procedures in patients with coronary-artery disease. Anesthesiology 1979; 51: 393-7.

5 Gobel FL, Nordstrom LA, Nelson RR, Jorgensen $C R$, Wang $Y$. The rate pressure product as an index of myocardial consumption during exercise in patients with angina pectoris. Circulation 1978; 57: 549-56. 
6 Cokkinos DV, Voridis EM. Constancy of pressure-rate product in pacing induced angina pectoris. Br Heart $\mathrm{J}$ 1976; 38: 39-42.

7 Wilkinson PL, Tyberg JV, Moyers JR, White AE. Correlates of myocardial oxygen consumption when afterload changes during halothane anaesthesia in dogs. Anesth Analg 1980; 59: 233-9.

8 Barash PG, Kopriva CJ. The rate pressure product in clinical anesthesia: boon or bane? Anesth Analg 1980; 59: 229-31.

9 Kennedy HL. Ambulatory (Holter) electrocradiography and myocardial ischemia. Am Heart J 1989; 117: 164-76.

$10^{\circ}$ Balasubramanian V, Lahiri A, Green $H L$, Stott FD, Raftery EB. Ambulatory ST segment monitoring. Problcms, pitfalls, solutions and clinical application. Br Heart J 1980; 44: 419-25.

$11 K r u c o f f W$. Poor performance of lead V5 in single and dual channel ST-segment monitoring during coronary occlusion. J Electrocardiology 1988; 21: S30-34.

12 Barnard RJ, Buckberg GD, Duncan HW. Limitations of the standard transthoracic electrocardiogram in detecting subendocardial ischemia. Am Heart J 1980; 99: 476-82.

13 Chaitman BR, Bourassa MG, Wagniart P, Corbara F, Ferguson $R J$. Improved efficiency of treadmill exercise testing using a multiple lead ECG system and basic hemodynamic exercise response. Circulation 1978; 57: 71-9.

14 Mason RE, Likar I, Biern RO, Ross RS. Multiple lead exercise electrocardiography. Experience in 107 normal subjects and 67 patients with angina pectoris, and comparison with coronary cinearteriography in 84 patients. Circulation 1967; 36: 517-25.

15 Fox KM, Selwyn AP, Shillingford JP. Projection of electrocardiographic signs in praecordial maps after exercise in patients with ischaemic heart disease. $\mathrm{Br}$ Heart $\mathrm{J}$ 1979; 42: 416-21

16 Fox KM, Selwyn AP, Oakley $D$, Shillingford JP. Relation between the precordial projection of S-T segment changes after exercise and coronary angiographic findings. Am J Cardiol 1979; 44: 1068-75.

17 Seegobin RD, Goodland FC, Wilmshurst TH et al. Postoperative myocardial damage in patients with coronary artery disease undergoing major non-cardiac surgery. Can J Anaesth (this issue).

18 Raby K, Goldman L, Creager MA et al. Correlation between preoperative ischemia and major cardiac events after peripheral vascular surgery. N Engl J Med 1989; 321: 1296-1300.

19 Steen PA, Tinker JH, Tarhan S. Myocardial reinfarction after anesthesia and surgery. JAMA 1978; 239: 2566-70.

20 Savage HR, Kissane JQ, Becher EL, Maddocks WQ,
Murtaugh JT, Dizadji $H$. Analysis of ambulatory electrocardiograms in 14 patients who experienced sudden cardiac death during monitoring. Clin Cardiol 1987; 10: 621-32.

21 Fleisher LA, Rosenbaum SH, Barash PG. Preoperative silent ischemia is a predictor of postoperative cardiac events in patients undergoing elective noncardiac surgery. Proceedings 12th Annual Mceting, Socicty of Cardiovascular Anesthesiologists 1990.

22 MacFarlane PW. Lead systems. In: MacFarlane PW, Veitch Lawrie TD (Eds.). Comprehensive Electrocardiology 1989: 315-52.

23 Lux RL. Mapping techniques. In: Macfarlane PW, Veitch Lawrie (Eds.). Comprehensive Electrocardiology 1989: 1001-14.

24 De Ambroggi L, Musso E, Taccardi B. Body surface mapping. In: Macfarlane PW, Veitch Lawrie (Eds.). Comprehensive Electrocardiology, 1989: 1015-49.

25 Nakajima T, Kawakubo $K$, Toda I et al. ST-T isointegral analysis of exercise stress body surface mapping for identifying ischemic areas in patients with angina pectoris. Am Heart J 1988; 115: 1013-21.

26 Gardner MJ. Body surface potential mapping. Medicine North America 4. 1990; 4: 440-44.

27 Bashour TT, Myler RK, Andrae GE, Stertzer SH, Clark $D A$, Ryan CJM. Current concepts in unstable myocardial ischemia. Am Heart J 1988; 115: 850-61.

28 Kong B, Heo J, Iskandrian AS. The duration of ST segment depression as an indicator of the pathophysiology of myocardial ischemia. Am Heart J 1989; 118 : 195-7.

29 Mudge GH, Grossman W, Mills RM, Lesch M, Braunwald $E$. Reflex increase in coronary vascular resistance in patients with ischemic heart disease. N Engl J Med 1976; 295: 1333-6.

30 Verrier RL, Hagestad EL, Lown B. Delayed myocardial ischemia induced by anger. Circulation 1987; 75: 249-54.

31 Hagestad EL, Verrier RL. Delayed myocardial ischemia following the cessation of sympathetic stimulation. Am Heart J 1988; 115: 45-53.

32 Boudoulas H, Rittgers SE, Lewis RP, Leier CV, Weissler $A M$. Changes in diastolic time with various pharmacologic agents. Implication for myocardial perfusion. Circulation 1979; 60: 164-9.

33 Geft IL, Fishbein MC. Ninomiya $K$ et al. Intermittent bricf periods of ischemia have a cumulative effect and may cause myocardial necrosis. Circulation 1982; 66: 1150-3.

34 Braunwald E, Kloner RA. The stunned myocardium: prolonged, post ischemic ventricular dysfunction. Circulation 1982; 66: 1146-9.

35 Rahimtoola SH. The hibernating myocardium. Am Heart J 1989; 117: 211-21. 
36 Deanfield JE, Shea M, Ribiero $P$ et al. Transient STsegment depression as a marker of myocardial ischemia during daily life. Am J Cardiol 1984; 54: 1195-200.

37 Kannel WB. Detection and management of patients with silent myocardial ischemia. Am Heart J 1989; 117: 221-6.

38 Sheps DS. Heiss $G$. Sudden death and silent myocardial ischemia. Am Heart J 1989; 117; 177-84.

39 Moss AJ, Benhorin J. Prognosis after a first myocardial infarction. N Engl J Med 1990; 322: 743-53.

40 Stratmann $H G$, Kennedy $H L$. Evaluation of coronary artery disease in the patient unable to exercise: alternatives to exercise stress testing. Am Heart J 1989; 117 : 1344-65.

41 Johnson SM, Mauritson DR, Winniford MD et al. Continuous electrocardiographic monitoring in patients with unstable angina pectoris: identification of high risk subgroup with severe coronary artery disease, variant angina, and/or impaired early prognosis. Am Heart J 1982; 103: 4-12.

42 Coy KM, Imperi GA, Lambert CR, Pepine CJ. Silent myocardial ischaemia during daily activities in asymptomatic men with positive exercise test responses. Am J Cardiol 1987; 59: 45-9.

43 Knight AA, Hollenberg M, London MJ, Mangano $D T$. Myocardial ischaemia in patients awaiting coronary artery bypass grafting. Am Heart J 1989; 117 : 1189-95.

44 Waters DD, Szlachcic J, Bonan R, Douglas Miller D, Dauwe $F$, Therous $P$. Comparative testing of exercise, cold pressor and ergonovine testing in provoking attacks of variant angina in paticnts with active disease. Circulation 1983; 67: 310-5.

45 David D, Lang RM, Borow KM. Clinical utility of excrcise, pacing, and pharmacologic stress testing for the noninvasive determination of myocardial contractility and reserve. Am Heart J 1988; 116: 235-47. 